\title{
INDEPENDENCIA POLÍTICA Y TRANSFORMACIÓN DE UNA METRÓPOLI COLONIAL: LA CIUDAD DE MÉXICO VISTA POR TRES BRITANICOS. 1821-1841
}

\author{
POR
}

\author{
EULALIA RIBERA CARBÓ
}

\begin{abstract}
...para gozar de una verdadera vista de noche tendréis que subir a la «azotea», y contemplar a México dormido a vuestros pies; todo el valle y la ciudad misma flotando en el plenilunio; la altísima bóveda azul engastada de estrellas y mientras las montañas se bañan en plata, los blancos volcanes parecen unir tierra y cielo. En esto, aun el genio de Salvatore desfallecería; es necesario evocar el fantasma de Byron. El lápiz es impotente. Sólo la poesía puede dar una pálida idea de una escena tan maravillosamente bella.
\end{abstract}

Madame Calderón de la Barca

El desmoronamiento del antiguo régimen

El esplendor de la España imperial tocaba a su fin. Durante el siglo xVIII Inglaterra y Francia habían consolidado una estructura capitalista mercantil que dejaba al país ibérico en una situación muy desventajosa en la competencia por la hegemonía mundial, y su gran extensión colonial poco le valía en comparación con las ganancias que aquellos obtenían de sus territorios ultramarinos.

Eulalia Ribera Carbó. Universidad Autónoma de México.

Estudios Geográficos

Tomo LVIII, n. ${ }^{\circ} 226$, enero-marzo 1997 
En un intento de resultados dudosos por salvar a la nave que se iba a pique, la monarquía borbónica inició una política centralizadora del poder y armó su plan de reformas encaminadas al control económico efectivo de los territorios del imperio. Así, en 1765 desembarcaba en Veracruz el ilustrado José de Gálvez para poner en marcha el plan reformista que, dicho en pocas palabras, pretendía lograr la modernización de las estructuras productivas para fortalecer la economía y aumentar las rentas de la colonia. Había que centralizar el poder transfiriendo al Estado el control de la vida económica, simplificar la administración pública y acabar con el monopolio de Cádiz para liberar al comercio. Y esto sólo era posible buscando el apoyo en los comerciantes capitalistas y en los ricos mineros de la Nueva España, que se fortalecieron en su ya de por sí privilegiada situación (Halperin, 1969).

Efectivamente, en la segunda mitad del siglo aquellas tierras norteamericanas vivieron un considerable crecimiento económico, y en el setecientos México fue la región más rica, más poblada y significativa para la economía europea, de una Hispanoamérica marcada por tres siglos de colonización. Por un lado, una gran expansión minera en el norte del país, y junto con ella la de la ganadería que tenía su mercado principal de consumo en los centros mineros, y por otro, el fortalecimiento del comercio y el avance de la agricultura de mercado presionando sobre las tierras maiceras del altiplano central.

La clase alta dominante quedó claramente dividida en los poderosos criollos mineros, y los peninsulares comerciantes y terratenientes favorecidos por la restructuración mercantil y la hegemonía de Veracruz, unos y otros haciéndose escandalosamente ricos al tiempo que la Nueva España, en menos de cincuenta años, doblaba su población a más de seis millones de habitantes a finales del siglo, y no precisamente a base de gente potentada. La gran expansión demográfíca se llevó a cabo sobre todo en el sector agrícola-artesano de autoconsumo, y precisamente cuando el avance de los cultivos de explotación marginaba cada vez más a los campesinos del dominio de la tierra (Brading, 1983).

En resumidas cuentas, las reformas borbónicas resultaron un elemento clave en el desencadenamiento de las inquietudes independentistas, porque la reforma administrativa aumentó la presión impositi- 
va del poder central sobre los grupos locales de poder, la clase media no encontró lugar en las filas de la burocracia y del clero ocupadas por peninsulares, muchos empleados criollos fueron echados de la administración, y los grandes contingentes campesinos sin tierras que llegaron a la ciudad engrosaron las filas de «léperos» y constituyeron materia dispuesta para la revuelta.

La guerra con la Gran Bretaña que ya dominaba el Atlántico fue separando progresivamente a España de sus colonias, e hizo cada vez más difícil el mantenimiento del monopolio comercial. Poco a poco fueron autorizándose medidas de apertura de la Nueva España a otras regiones del mundo, que dieron a los comerciantes novohispanos una desmedida confianza en sus propias fuerzas económicas, y de esta forma fue quedando abonado el terreno para el fuego que estaba a punto de incendiar al sometido continente.

Todas las revoluciones hispanoamericanas de independencia se iniciaron como intentos de los sectores criollos de las oligarquías urbanas por sustituir a los peninsulares en el ejercicio del poder político. Pero enseguida, al menos en los virreinatos de la Nueva España y la Nueva Granada, aquella primera etapa fue rebasada por rebeliones indias y mestizas que esgrimían reivindicaciones propias. En México, en el contorno agrícola de la zona minera, Miguel Hidalgo y Costilla acaudilló a los peones rurales y mineros del maíz y la plata; en las tierras centrales que bajan hacia el Pacífico, José María Morelos y Pavón lo hizo con los comuneros y pequeños propietarios rurales, y con los rancheros que eran lentamente marginados de sus tierras dedicadas al autoconsumo y al comercio local por el avance de cultivos de exportación.

Bien pronto criollos y peninsulares dieron respuesta, y frente a un enemigo común que amenazaba tangiblemente sus privilegios, se unieron para sofocar el alzamiento rural.

Pero el triunfo liberal de Riego en España precipitó la independencia de México. Las leyes liberales españolas mostraban semejanzas peligrosas con algunas propuestas jacobinas de los líderes de la independencia mexicana, en esos años ya derrotados y muertos, y entonces los peninsulares y algunos sectores criollos, reticentes a la separación de España, abrazaron la causa independentista para evitar la instauración de la legislación gaditana (Chaunu, 1973). 
Un país nuevo y convulsionado

Once años de revolución no podían pasar sin dejar profundas huellas en la recién nacida nación independiente. En 1821 Mexico se enfrentaba a un panorama complicado, heredado por una revolución complicada a su vez, que había despertado antiguos conflictos agrarios, raciales, sociales y regionales.

Su expresión primera y más evidente fue la violencia generalizada que se apoderó de la vida cotidiana. El uso de armas se había difundido. La rebelión iniciada por las elites criollas se había ido saliendo de cauce con los levantamientos populares, y el esfuerzo de aquellas por aplastarlos generó un inmenso cuerpo de militares, que según convenía defendían causas diversas. Pero terminada la guerra, la militarización era un fenómeno imprescindible para el mantenimiento de un mínimo orden social, que a la vez resultaba extremadamente costoso para un país que resbalaba hacia la bancarrota económica. En los primeros años independientes el ejército se convirtió en una sanguijuela que llegó a absorber entre el $70 \%$ y el $80 \%$ de los fondos del erario público, y era un lastre que no dejaba al esperanzado Mexico salir a flote. Y además era inseguro. El ejército era el garante de la estabilidad política y simultáneamente resultaba el factor principal de la inestabilidad (Argüello, 1989).

La consolidación de un poder central se hacía imposible, y la reafirmación de los múltiples poderes caciquiles que intentaban convertirse en caudillos nacionales hacía cosa normal los constantes alzamientos armados, que tenían como objetivo el control de la capital. Golpes de estado, cuartelazos y «revoluciones» transtornaron la vida diaria de los mexicanos. Proliferaron los asaltantes de caminos, y como en todo el mundo decimonónico en transformación hacia el nuevo orden burgués, surgió el bandolero social.

Pero la violencia no fue el único legado de la revolución. El ámbito americano no había escapado a la influencia de las ideas del Siglo de las Luces, y los promotores de la independencia, imbuidos de liberalismo, defendieron desde un principio la libertad de comercio. Rotos los lazos comerciales, el sistema mercantil sufrió profundas transformaciones, y en la segunda década del novecientos Hispanoamérica toda se abrió al comercio extranjero.

Sin embargo, no llegaban capitales. Los países europeos de avan-

$$
-98-
$$


zada apenas satisfacían sus propias necesidades de capital en la primera etapa ferroviaria de la industrialización, y en esos años lo único que buscaban en la América Latina eran mercados para su producción industrial y adueñarse de la dirección del comercio. Los criollos, que habían creído prosperar con la ruina de los españoles que controlaban la estructura mercantil de la Colonia, quedaron también derrotados cuando los sectores más ricos del comercio pasaron a manos extranjeras. Inglaterra ocupó el lugar de España, y prolongó aquel sistema monopolista, que antes era controlado jurídicamente y ahora lo sería por mecanismos económicos.

El flujo del comercio ultramarino arruinó la producción artesana local y la economía resintió gravemente el aumento desenfrenado de las importaciones. México apenas se defendía con los impuestos aduaneros que representaban una renta considerable para el Estado.

Pero de todo el caos revolucionario, fueron tal vez las élites urbanas las que resintieron más visiblemente los embates de los vaivenes bélicos. La guerra les arrebató cuantiosas fortunas, y además tuvieron que aceptar, no sin desespero, el ascenso social de algunos sectores terratenientes que durante la Colonia habían mantenido una posición subordinada, junto con el surgimiento de numerosos prestamistas, que en virtud de la miseria del tesoro público, se enriquecían a pasos agigantados. Irremediablemente las oligarquías ciudadanas tradicionales tendrían que acostumbrarse a ocupar una inferior y nueva posición en aquel orden, en que militares de origen social «dudoso» asumían el papel cupular en la nueva jerarquía social.

La guerra había traído consigo la crisis de las actividades que habían dado el gran empuje urbano a finales del siglo xviII: la minería, el comercio local e internacional, la manufactura incipiente. Se había roto la red comercial que aglutinaba a toda la región central del virreinato alrededor de los mercados de la Ciudad de México, y que permitía a sus élites el control del campo. El país se ruralizó aumentando sensiblemente la regionalización, y los capitalinos privilegiados se enfrentaron a la lucha pertinaz de los poderosos del campo por acabar con el dominio indiscutible de la ciudad durante los tres siglos de colonia. El esplendor urbano se estancaba (Romero, 1976).

Los primeros lustros independientes fueron de triunfo conservador. Los liberales defendían principios federalistas que abrían peli-

$$
-99-
$$


grosos canales a sectores que tan cuidadosamente se había querido mantener marginados, y aquellos que sentían amenazado algún mínimo o no tan mínimo privilegio, se convertian en defensores de la causa conservadora. Creían en que la reconciliación de criollos mineros y terratenientes con los comerciantes españoles permitiría dar un apoyo sólido al nuevo orden en que la Gran Bretaña ocuparía el papel de España.

Pero los niveles de la economía colonial no se recuperaban, la vida se degradaba, los gastos del ejército eran excesivos y no fluían capitales para impulsar a la minería. El sueño de progreso y de riqueza tan esperado no llegaba, y se culpaba de ello a la guerra, a la inestabilidad política y al omnipresente poder militar. El desencanto ocupaba el lugar de aquella primera euforia de los herederos de la independencia (Halperin, 1969).

México abre sus puertas al mundo: los viajeros

La Nueva España había sido celosamente guardada. Durante trescientos años España había intentado reservar para sí todas las bondades de aquel pródigo pedazo del Nuevo Mundo, y había cerrado las puertas a los ojos interesados de sus ávidos vecinos europeos. México las abría con gran fe en su propio potencial y en el brillante futuro que le aguardaba como país independiente, y confiado, daba la entrada a las ambiciones de los países que consolidaban sus estructuras capitalistas e iniciaban la carrera imperialista por todas las latitudes. Desde luego que las tierras tan alabadas por el barón Von Humboldt resultaban indudablemente atractivas.

La Gran Bretaña, que era la potencia comercial e industrial de la Europa del momento, junto con la ascendente federación norteamericana fueron los dos grandes adversarios en la disputa por apoderarse del nuevo botín, y de la que al final saldría ventajosa la vecina hermana mayor republicana, tan ingenuamente admirada por los políticos liberales.

Pero de momento, recién finalizada la revolución, y atraídos por la novedad de la república y la posibilidad de realizar fructíferas inversiones, viajeros de todo tipo llegaron al país: aventureros, comerciantes, representantes de compañías extranjeras y diplomáticos, que 
según sus propios intereses sondeaban atentos la situación política, social y económica. Eran la punta de lanza del capitalismo industrial y mercantil. Y México, que en su irreflexivo entusiasmo independentista se había propuesto negar los tres siglos de historia colonial, y romper los lazos de unión con la anquilosada y retardataria España para justiflcarse en el pasado prehispánico, quería aparecer nueva, sin sombras de leyenda negra y antiespañola a los ojos del mundo (Ortega, 1987).

Pero no lo logró, porque los extranjeros vieron en México a la hija de la madre y los tópicos perduraron. Fanático, indolente e incapaz se pintó México ante la mirada de aquellas puritanas y capitalistas mentes anglosajonas, que incorporaron al país a una vieja guerra planteada entre la implacable modernidad inglesa y el viejo orden representado por España. Se complacían de la independencia de México, criticando el monopolio comercial al que había estado sujeto, culpando a la metrópoli y a su sistema de gobierno despótico del estancamiento generalizado de la vida de su excolonia.

Había que acabar con su herencia corruptora, para que ese México fervientemente católico y ridículamente republicano pudiera progresar a través del ejemplo y el contacto con la tradición ílustrada y progresista del parlamentarismo anglosajón. Cargados de principios liberales, los extranjeros visitantes coincidían en sus críticas a las políticas aduaneras proteccionistas, que ponían trabas al proceso que convertiría a México en exportador de materias primas e importador de bienes industriales, dentro de la nueva división internacional del trabajo.

Al mismo tiempo, los viajeros de aquellas décadas fueron hombres de su tiempo, y por lo tanto permeados de un espíritu romántico que les hacia exaltarse a la vista del exuberante, extenso y variado paisaje mexicano. Se sorprendían del urbanismo de las ciudades, de sus casas y sus palacios, especialmente en la capital, que sin duda fue la ciudad del imperio español del siglo xviII en la que más se invirtió en obras urbanas. Se admiraban del cuadro que conformaba su gente. Más que analizar los paisajes los percibían, y describían los ambientes. Y todos, llegaron a México interesados y animados por las descripciones que habian leído en el célebre Ensayo Político de la Nueva España de Humboldt.

Hay por lo tanto una gran similitud de contenido y de juicio en

$$
-101-
$$


los trabajos de los viajeros en México, porque a pesar de existir numerosos plagios, es insoslayable la semejanza de los temas tratados y de las circunstancias históricas en que los autores habían forjado sus criterios.

Fue a través de los testimonios escritos de tres de estos visitantes, como pretendimos asomarnos al retrato de una ciudad que resurgía de las cenizas de una revolución que había durado once años.

El inglés William T. Penny es el autor anónimo de unas Cartas familiares y un Diario, redactados entre 1824 y 1826, y que fue identificado no sin algunas reservas. Era un comerciante de buena posición, que según parece tenía parientes residiendo en México, dueños de una empresa comercial. Incansable, realiza un viaje por el país, del que hace observaciones desde una perspectiva evidentemente mercantil (Penny, 1828).

El capitán George Francis Lyon, de la Marina Real Inglesa, visitó México una vez licenciado tras la derrota de Napoleón. Vino como comisionado de las compañías mineras de Real del Monte y Bolaños, que después de la independencia habían pasado a manos inglesas. Recorrió el país con medios y formas muy modestos en visita de inspección a los distritos mineros, y escribió un diario que fue publicado en Londres en 1828: Residencia en México, 1826. Diario de una gira con estancia en la República de México (Lyon, 1828).

Y por último la escocesa Frances Erskine Inglis, que vino a México casada con el primer ministro plenipotenciario de España después de la declaración de independencia. Mejor conocida con el nombre del marido, madame Calderón de la Barca era una mujer muy preparada para su tiempo, y de su estancia en nuestro país entre diciembre de 1839 y enero de 1842, dejó una serie de cartas dirigidas a su familia que residía en Boston y que se publicó en Londres y en Boston en 1843. La vida en México. Durante una residencia de dos años en ese país ofrece un panorama inigualable por la belleza de sus descripciones y por la sensibilidad extraordinaria de su autora, que aunque tenía pocos conocimientos del país al que llegaba -fuera de los obligatorios para cualquier viajero ilustrado: Humboldt, Clavijero, las cartas de Hernán Cortes y poca cosa más- tuvo la capacidad de entender, mejor que otros, la idiosincrasia de un pueblo que luchaba por conformar su propia nacionalidad (Calderón, 1843). 
La ciudad de los palacios

La ciudad ha sido en la historia el escenario y la culminación de los progresos de la humanidad; espejo del orden económico, espacio de la movilidad social, terreno para la acción política y cuna de revoluciones intelectuales.

Sin duda entonces, el estudio de una ciudad siempre será apasionante, y en el caso de la de México no se necesitan demasiadas palabras para justificarlo. Grandiosa por si misma y eje de una historia agitada y extraordinaria, la llamada «ciudad de los palacios» ha sido la caja de resonancia de las luchas sociales y políticas del país. Con sus sólidas edificaciones y su estructura cuadrangular y espaciosa, fue creciendo durante los años de colonia hasta alcanzar su máximo esplendor en tiempo del ilustrado virrey Revillagigedo, que mandó proyectos importantes para limpiarla y reordenarla.

Pero los planes quedaron interrumpidos por la guerra de independencia, y la ciudad que la sobrevivió no sufrió transformaciones significativas sino hasta la segunda mitad del siglo, cuando su traza fue alterada por las guerras de reforma y las leyes de desamortización (De Gortari, 1988). Durante las tres primeras décadas de vida independiente no hubo modificaciones serias en su estructura, pero sí en la imagen del nuevo orden que reflejaba. El gran cambio en el equilibrio colonial alcanzó su máxima expresión en la ciudad, donde se hacía manifiesta la militarización, la violencia, el caos administrativo, la bancarrota del erario público, las alteraciones en la estructura social y las expresiones intelectuales e ideológicas de los agitados años que siguieron a la independencia.

En esa ciudad convulsionada, decaída, escenario de fiestas y tradiciones, y magnífico testigo de la riqueza de tiempos pasados, fue la que encontraron nuestros viajeros.

\section{Ciudad y paisaje}

$\mathrm{Al}$ asomar por cualesquiera de las sierras montañosas que encierran al Valle de México, la vista de la ciudad en aquél marco producía la primera y esperada impresión: 
«el gran Valle de México, con su hermosa ciudad (...), rodeada de divergentes y sombreados paseos, brillantes campos y pintorescas haciendas. El gran Lago de Tescuco (sic) se halla inmediatamente atrás, sombreado por una baja y flotante nube de exhalaciones de su superficie, la que ocultaba a nuestra vista las bases de los volcanes Popocatépetl e Iztaccíhuatl, mientras que sus cumbres nevadas brillaban al resplandor de los rayos del sol, (...) su animada blancura y su carencia de humo, la magnitud de sus iglesias y la extrema regularidad de su estructura, le daban un aspecto que jamás se ha podido ver en una ciudad europea, y la declaran única, tal vez inigualable en su estilo.» (Lyon, 1828).

No se cansan de insistir en lo grandioso del paisaje del que la ciudad forma parte, y cada vez que realizan una excursión por los alrededores vuelven a comentarlo extasiados. Desde Chapultepec «la vista (...) es de una grandeza imposible de imaginar», desde el occidente, en el camino al Desierto de los Leones, «la vista (...) nunca alcanzó un efecto tan asombroso (...) la antigua ciudad, con sus torres, legos y volcanes, recreábase en un baño de luz solar», y desde la Sierra Nevada al oriente, «el panorama (...) es grandioso y está más allá de descripción» (Lyon, 1828; Calderón, 1843).

\section{Estructura urbana}

Una vez en la ciudad, también quedaron profundamente admirados con la traza recta, uniforme y ancha de las calles, que resultaba casi sin excepción en una bella perspectiva, con la magnitud de las plazas públicas, los palacios con sus hermosas fachadas, y las grandes casas de techos planos y azoteas, balcones con balaustradas y ventanas con rejas de hierro. La suntuosidad y tamaño de los numerosos conventos e iglesias, y el inmenso Palacio Nacional, la catedral, el Monte de Piedad y los edificios de altas arquerías, enmarcando juntos la impresionante plaza mayor de la capital.

En palabras de Penny: «tal como para convencernos enseguida que la fama no ha proclamado demasiado ruidosamente su magnificencia y grandeza.» (Penny, 1828). El Palacio de Minería, sede de la escuela de ingeniería, la Universidad, la Academia, el Colegio de las Vizcaínas, el Palacio del Arzobispo, la Casa de Moneda, el Museo, los

$$
-104-
$$


dos acueductos de piedra, y la colosal estatua ecuestre de Carlos IV son mencionados con detenida atención.

Comentan sobre la construcción rectangular de las casas mexicanas, su patio central adornado con macetas, y el corredor abierto para llevar a todas partes del edificio. Casas que si en un primer momento pudieron resultarles demasiado grandes e incómodas, y algo descuidadas en su acabado dado que puertas y ventanas cerraban de manera floja, más tarde les parecen adecuadas al clima de «eterna primavera». Inclusive de los conventos que visita, la señora Calderón de la Barca reflexiona sobre lo bien avenido de la clausura y la forma de construcción, que con sus corredores y patios permite una ventilación que hace menos duro el encierro.

Los grandes paseos de Bucareli, de La Viga y la Alameda con sus árboles, las fuentes y la vista de las montañas, todo, en fin, daba a la ciudad de los legos un aire de grandeza y un noble aspecto. En ello concuerdan los tres visitantes.

\section{Descuido, ruina y violencia}

Pero no hace falta recordar que no todo era nobleza. Frances Calderón habla, aunque muy brevemente, de los suburbios pobres de la ciudad y su estado ruinoso, sucio y con una terrible «promiscuidad de olores». Tampoco podemos olvidar que el país salía casi apenas de una revolución, seguía en guerras internas, y que en vista de que más de la mitad de los fondos públicos los absorbía el ejército, poco o nada debía ser lo que se dedicaba al mantenimiento y restauración de la ciudad, que lo acusaba ostensiblemente.

La escocesa se plañe de ello y comenta constantemente la pena de que el «talón de hierro de la revolución» mostrara sus terribles huellas en la magnificencia que transmitía a pesar de todo la ciudad. El Palacio de Iturbide casi en ruinas, el Castillo de Chapultepec solitario, abandonado y destruyéndose con rapidez, el Jardín Botánico y el Museo como espléndidos monumentos abandonados, Minería como «una enorme pajarera de oro en donde se albergan unos cuantos gorriones». La Academia con sus bellas y mutiladas colecciones, por todas partes restos de edificios y palacios, casas sin techos, muros y arcadas destruidos, conventos en ruinas, y el mal estado de calles y aceras. 
La decadencia de las bellas artes en México, asevera madame Calderón, es una de las pruebas «de los lastimosos efectos producidos por años de guerras intestinas y el desbarato de los gobiernos»; tantas antiguas instituciones españolas al borde de la ruina y por las que no se había hecho nada desde la independencia. Se explica entonces la nostalgia de muchos por los tiempos pasados, y en un breve párrafo nos retrata con una contundencia implacable la situación de México en ese momento: «El pasado es nada, y al fin y al cabo el futuro se convertirá en el pasado, dice Lord Byron. Aquí el Pasado está en todas partes; ¿y el Futuro? Conteste quien pueda.» (Calderón, 1843).

La violencia es la otra triste realidad que retrata a la ciudad. El problema de los ladrones, la cotidianeidad de crímenes que no causaban ya demasiada impresión, y la inseguridad para los transeúntes. Todos los caminos de la República infestados de asaltantes «fruto de la guerra civil», y que «bajo la capa de insurgentes (...) han arruinado a todo el comercio, y (...) propagaron por todas partes el robo y el asesinato.» En 1840, pronunciamientos y cuartelazos que hacían cosa más o menos normal el tiroteo y los cañonazos por las calles, los léperos armados, las casas céntricas balaceadas, y la gente desplazándose a los suburbios como el de San Cosme sin amotinamientos ni confusión, y con una sorprendente y relativa calma (Calderón, 1843).

\section{Comercio}

A pesar de todo la ciudad funcionaba; por las garitas entraban los productos del campo que la abastecían, y el comercio en todas sus formas seguía dando parte de su carácter a la capital. Como lógicamente correspondía a sus intereses personales, Francis Lyon y William Penny ponen especial énfasis en el tema. Cada día, las canoas cargadas de legumbres, de frutas, de flores, de forrajes, de madera y de ollas de barro llegaban a la ciudad desde las zonas chinamperas del sur del valle por el canal de La Viga. Después de pasar la aduana y pagar los impuestos, las mercancías eran colocadas mayoritariamente en el Parián, ese gran mercado al sur del Zócalo, y que según la señora Calderón destruía la nobleza de la plaza. Era un edificio de planta rectangular con entradas custodiadas por centinelas, y con un laberinto de pasillos en el interior distribuyendo las tiendas, que aún 
sin ventanas, se abrían con sus diversas puertas, y estaban llenas de anaqueles con los artículos caprichosamente ordenados.

A Lyon las tiendas le parecen bien surtidas y numerosas, pero habla de que el comercio más intenso entre la población común de la ciudad se llevaba a cabo en los Portales, donde de forma amontonada sobre cajones, o directamente en el suelo, y sólo aparentemente desordenada, se vendía toda suerte de artículos como cuchillería, joyería de fantasía, figuras de cera, muñecas, vestidos de colores chillones, zapatos, libros, etc.

Penny menciona la existencia de cinco casas inglesas y dos estadounidenses, a través de las cuales se realizaban importaciones para surtir a los comerciantes de las tiendas establecidas del Portal, y generalmente pertenecientes a viejos españoles que intentaban adaptarse al nuevo sistema de libre comercio. Según él, los extranjeros -entiéndase que el término no incluye a los españoles- proveían en buena parte a los comerciantes de menudeo de la ciudad. En el Parián ya podían encontrarse toda clase de productos británicos. y aún hubieran podido introducirse más telas inglesas y alemanas a no ser por la «equivocada política gubernamental» que lo impedía. Para el inglés, los comerciantes compatriotas suyos ganaban terreno rápidamente frente a la opinión pública, gracias a su buena fe y su reputación en los negocios (Penny, 1828).

\section{Servicios e higiene}

La señora Calderón, que vivió aristocráticamente en la ciudad, en vez de recorrer mercados visitaba conventos, hospitales e instituciones de caridad. Iba al hospital para leprosos en los llanos cerca de San Lázaro, al de dementes en el exconvento de San Hipólito que era grande y de una «belleza solitaria», con su amplio y aireado refectorio y la magnífica cocina de bóvedas altas. En el hospital de Jesús cada enfermo tenía su cuarto o al menos una estancia dividida con cortinas, y donde reinaban un asombroso orden, aseo y eficacia. El hospital de San Juan de Dios estaba también limpio y tenía cuartos aireados y decentes. que hacían olvidar que se trataba de un hospital. La Cuna era administrada por personas de la «alta sociedad» mexicana, la Casa de las Locas sufría por falta de fondos, y la cárcel pú- 
blica. aunque estaba en un edificio grande y espacioso, parecía terrible al no hacer distinciones de grado entre los criminales recluidos en ella. Y el hermoso y arbolado panteón de Santa Paula a las afueras de la ciudad resultaba un apreciado lugar de paseo para la escocesa.

En cambio, el pobre Lyon no parece haber disfrutado de iguales deleites, cuando se quejaba amargamente de los desagradables e incómodos mesones en que se hospedaba: «fondas para otros que no sean arrieros o léperos son muy raras, y un extranjero que se encontrase solo viviría peor en México que los pobres diablos». En cambio madame Calderón, asombrada con la pulcritud de los hospitales, se horrorizaba con la suciedad del oscuro teatro, foco de malos olores, de la suciedad de la catedral por donde pululaban perros y donde arrodillarse en el suelo resultaba terriblemente desagradable, y de la falta de limpieza general reinante en la ciudad, por lo visto acentuada en el centro donde, las enfermedades y las epidemias eran mas comunes.

\section{Perfil social y vida en la ciudad}

Como ya se mencionó líneas arriba, el cuadro humano fue de las cosas que más acaparó la atención de los viajeros, quienes hicieron reflexiones y se asombraron de la estructura y la dinámica del mosaico social.

Hablan de los lujos de las escasas y pudientes familias de la oligarquía, que vivían desahogadas en visitas y tertulias diarias, por cierto curiosas para ellos por la familiaridad y vivacidad en el trato y la plática, que asistían al teatro donde las mujeres fumaban y atendían a todo más que a la escena -por otra parte mal- y de vez en cuando a la ópera, cuando alguna compañía italiana invitada llegaba a la ciudad. Les sorprende la gran preocupación por poseer uno o varios carruajes, absolutamente imprescindibles para una familia que presumiera de cierta categoría en el escalafón social, y de lo poco elegante que se consideraba el paseo a pie. Después de la misa de la mañana, raramente podía verse a una señora caminando por las calles, con excepción de las que iban a las tiendas, pero eso sí, siempre acompañadas de un criado.

$$
-108-
$$


Las personas más distinguidas de México se quejaban de la falta de instituciones educativas de categoría adecuada para la formación de sus hijos, y de la consecuente necesidad de enviarlos al extranjero; la educación de las «señoras» y «señoritas» mexicanas dejaba mucho que desear y de hecho, no existían escuelas que realmente merecieran este nombre La comparación con las mujeres inglesas y norteamericanas resultaba en un gran contraste, que sólo se explicaba por la herencia del farniente de las españolas.

¡Qué vida ostentosa y derrochadora! La señora Calderón de la Barca se asombra de lo antirrepublicano de muchas escenas cotidianas, y de ese contraste abrumador entre la riqueza y la miseria: «aquí el pueblo apenas anda vestido, apenas existe el eslabón entre la frazada y el raso, entre las amapolas y los diamantes» (Calderón, 1843). $Y$ efectivamente, muy pocos disfrutaban de esa vida holgada que transcurría agradablemente con las constantes excursiones y visitas a Chapultepec, a Tacubaya, a Tacuba y a San Angel en las cercanías de la ciudad, y los placenteros días de campo y cabalgatas por los alrededores. La egoísta felicidad de esos privilegiados se empañaba con la insistente presencia de todo un ejército de desheredados que se encargaba de recordar que ellos también eran parte de la Ciudad de México.

Los suaves, sufridos y despreciados indios, difícilmente superables en su humildad y cortesía, y ocupados en los empleos más ínfimos, o vendiendo los productos de sus pequeñas parcelas en los mercados de la ciudad. Vestidos con calzones de manta y ellas con enaguas oscuras, blusas de algodón, rebozo, huaraches y trenzas adornadas con cintas, se les veía frecuentemente embriagados cerca de las pulquerías. Y despues, los desagradables léperos, solo semivestidos con harapos y la mayor parte sin casa donde vivir, arremolinándose alrededor de los transeúntes con lastimeros quejidos y exhibiendo miserias para pedir limosna (Calderón, 1843).

Pero si algo admira a los tres británicos, es la convivencia de todos en los paseos, las iglesias y en la calle, las señoras en elegantísimos carruajes coqueteando con los caballeros a caballo, oficiales de uniforme, soldados vigilando el orden, indios y léperos, todos en un espectáculo lucido y de cada tarde en los paseos más importantes de la capital. La marquesa y la campesina arrodilladas rezando una junto a la otra en la catedral, y la aparente familiaridad en el trato entre

$$
-109-
$$


amos y criados, que de ninguna manera ocasionaba faltas de respeto. El Portal, decía Penny, es un México en miniatura donde comerciantes, arrieros, indios, léperos, damas y criados se mezclan «promiscuamente con la total independencia y el obstinado codeamiento de la igualdad republicana».

Al final, una Ciudad de México que transmitía una intensa impresión de alegría y jovialidad, inspirada por un cielo profundamente azul, y con el acompañamiento desde el amanecer de los gritos callejeros de los vendedores de carbón, mantequilla, cecina, gorditas, tejocotes, petates, dulces y lotería. Las peleas de gallos, los toros, los juegos de azar, las fiestas de la semana santa, las posadas decembrinas, los mercados, los puestos de refrescos, los bailes y los paseos, y todo, siempre enmarcado de flores y verde.

Una ciudad que contrastaba con la miserable situación del extenso campo mexicano. Una ciudad que quería arrancarse su semblante colonial, y que pronto iría adquiriendo los ropajes de la modernidad decimonónica. Una ciudad en la que se debatían los destinos del nuevo país independiente.

Pero dejémosle la última palabra a aquella mujer tan sensible y enamorada de México, que con gran entendimiento temía por la castigada, conflictiva y acechada nación:

«Todo está en decadencia y todo se va esfumando, y tal parece que los hombres confían en un futuro ignoto que quizas nunca verán. Se abandonó un sistema de gobierno y no existe ninguno en su lugar. Que estén alertas, no sea que al cabo de medio siglo despierten del error y se encuentren que la Catedral se ha transformado en sala de juntas, toda pintada de blanco; que las rejas han sido fundidas; que la plata se ha convertido en dólares; que las joyas de la Virgen se vendieron al mejor postor; que el piso ha sido lavado (lo cual no haría daño a nadie), y que todo está rodeado por una nueva y preciosa cerca, recién pintada de verde, y todo ello realizado por algunos de los artistas de la "despierta" y lejana República del Norte.» (Calderón, 1843). 


\section{BIBLIOGRAFÍA}

ARGUUELLO, Gilberto (1989): «El primer medio siglo de vida independiente (1821-1867)», México, un pueblo en la historia. México, Alianza Editorial Mexicana, t. 2. (El libro de bolsillo).

Brading, David A. (1983): Mineros y comerciantes en el México borbónico (1763-18101). México, Fondo de Cultura Económica.

Calderón de la Barca, Frances (1843): La vida en México. Durante una residencia de dos años en ese país. México, Porrúa, ed. 1987.

Chaunu, Pierre, Hobsbaum, Eric y Pierre, Vilar (1973): La independencia de América Latina. Buenos Aires, Ediciones Nueva Visión.

De Gortari, Hira y Hernández, Regina (1988): Memoria y encuentros: La Ciudad de México y el Distrito Federal (1824-1928). México, Departamento del Distrito Federal Instituto de Investigaciones, Dr. José María Luis Mora.

Geisse G., G. (1986): «Tres momentos históricos en la ciudad hispanoamericana del siglo XIX», Revista Latinoamericana de Estudios Urbano Regionales. Santiago, Instituto de Estudios Urbanos de la Facultad de Arquitectura y Bellas Artes de la Pontificia Universidad Católica de Chile, vol. XIII, n. ${ }^{\circ} 38$, diciembre.

GuTiÉREZ, Ramón (1992): Arquitectura y urbanismo en Iberoamérica. Madrid, Ediciones Cátedra, 2 ed. (Manuales Arte Cátedra).

HalPerin Dongui, Tulio (1980): «Las ciudades hispanoamericanas (1825-1914). El contexto económico social», en Revista Interamericana de Planificación. SIAP, vol. XIV, n. ${ }^{\circ} 55-56$, septiembre, diciembre.

Halperin Dongui, Tulio (1969): Historia Contemporánea de América Latina. Madrid, Alianza Editorial (El libro de bolsillo, 192).

Lyon, George F. (1828): «Residencia en México, 1826», en Diario de una gira con estancia en la República de México. México, Fondo de Cultura económica, ed. 1984.

Orozco y Berra, Manuel (1973): Historia de la Ciudad de México. Desde su fundación hasta 1854. México, Sepsetentas.

Ortega y Medina, Juan (1987): Zaguán abierto al México republicano (1820-1830). México, Universidad Nacional Autónoma de México.

Penny, William T. (1828): «México de 1824 a 1826; cartas al diario», en Zaguán abierto al México republicano (1820-1830). México, Universidad Nacional Autónoma de México, ed. 1987.

Rojas-Mix, Miguel A. (1978): El urbanismo, instrumento de dominio colonial. Barcelona, Muchnibe Editores.

Romero, José Luis (1976): Latinoamérica: las ciudades y las ideas. Buenos Aires, Siglo XXI ediciones.

VIlaR, Pierre (1981): Historia de España. Barcelona, Editorial Crítica, Grupo Editorial Grijalbo.

Resumen:-Después de once años de revolución y una vez lograda la independencia política en 1821, México quedó sumido en una difícil situación de crisis y transformación de su estructura económica, de reacomodo social, y de violencia generalizada y militarización costosa. El reflejo de ese país convulsionado fue el que encontraron los viajeros que visitaron la Ciudad de México en las primeras décadas de vida independiente, y quienes maravillados y sorprendidos con la grandeza y las particularidades de un mundo urbano tan distinto al suyo, comentan en diarios y cartas. 
Political independence and the transformation of a Colonial City: the town of Ménico as described by three British witness. 1821-1841.

ABSTRACT.-After eleven years of revolution, and once the political independence was achieved, Mexico remained in the middle of a difficult situation of economic crisis and transformation, social adjustments, generalized violence and a very expensive militarization. The image of that convulsed country was the one the travelers found on their visit to Mexico City during the first decades of independence, and the one they discussed in their letters and diaries, astonished and marveled by the greatness and the specificities of such a different urban world.

RESUMÉ.-Après onze ans de révolution et une fois obtenue l'indépendance politique en 1821, le Mexique resta soumis à une difficile situation de crise et de transformation de son structure économique, de réorganisation sociale, de violence généralisée et d'une couteuse militarization. L'image de ce pays bouleversé fut celle qui trouverent les voyageurs qui visitèrent la ville de México pendant les premiers décades de son independance, et qui furent surpris et emervaillés de la grandiosité et les particularités d'un monde urbain si different du leur, -comme ils le disaient sur leurs notes de voyage et sur leurs lettres-. 